\title{
Ketsueki-Gata Through American Eyes: Examining the Correlation Between Blood Type and Personality
}

\author{
Muni Tanmayi Bondu \\ Middleton High School, 4801 N 22nd St, Tampa, FL, 33610, U.S.A.; tanu.bondu@gmail.com
}

ABSTRACT: In Japan, "Ketsueki-gata" has been a belief for over 90 years. It states that a person's ABO blood group significantly contributes to their demeanor. This is comparable to astrology, but blood type is a genetic component of humans and personality may also be influenced by genes. As the 1990 Minnesota Twin Study showed, twins that were raised apart developed similar social attitudes although they grew up in different environments, showing a correlation between genes and personality. This study tests if blood type influences personality and seeks to establish credibility of the personality-blood type phenomenon. Through an online survey, participants were asked to provide their blood type and complete a personality test that measured levels of openness to experience, conscientiousness, extroversion, agreeableness, and neuroticism. Results were converted into scaled scores, averaged, graphed, and analyzed using CHI square. Through the statistical analysis of 100 adults, their personality tests using the Big 5 Personality Traits model, and their blood type, no correlation was found. The null hypothesis of the CHI Square test failed to be rejected leading to the conclusion that blood type does not influence personality.

KEYWORDS: Behavioral and Social Sciences; Physiological Psychology; Blood-Type Personality Correlation; Big 5 Personality Traits; Ketsueki-Gata.

\section{- Introduction}

A potentially pseudo-scientific belief that blood type influences personality began in 1927 with the publication "The Study of Temperament through Blood Type" by Tokeji Furukawa. ${ }^{1}$ The idea was extended in 1971 after Masahiko Nomi published "Understanding Affinity Through Blood Type." The term Ketsueki-gata became prominent in Japanese society, the term meaning blood type influences personality.

Blood types are categorized by the ABO Blood Grouping System. This system was discovered by Karl Landsteiner ${ }^{3}$ in 1901, publishing the $\mathrm{A}, \mathrm{B}, \mathrm{AB}$ and $\mathrm{O}$ system. The blood type is determined if an $\mathrm{A}$ or $\mathrm{B}$ antigen is present on their RBCs. There are 32 recognized blood groups but 4 that are most common as shown in Table 1 . $^{2,3}$

Table 1: This table shows the 4 most common blood types and their antigen/antibody makeup that distinguishes them from other blood types. Differences show the different makeup of each blood type.

\begin{tabular}{|l|}
\hline Type A: $\mathrm{A}$ antigens $+\mathrm{B}$ antibodies \\
\hline Type B: $\mathrm{B}$ antigens $+\mathrm{A}$ antibodies \\
\hline Type $\mathrm{AB}: \mathrm{AB}$ antigens + no antibodies \\
\hline Type O: No antigens $+\mathrm{A}$ and $\mathrm{B}$ antibodies \\
\hline
\end{tabular}

According to the American Psychological Association, personality is the different characteristics a person shows in thinking, feeling and behaving. ${ }^{4}$ The most common way to measure personality is "The Big 5 " which measures an individual in 5 factors: 1 . openness to experience, 2. conscientiousness, 3. extraversion, 4. agreeableness, and 5. neuroticism. ${ }^{5}$

As part of the Minnesota Twin Study, results have shown that personality may have a strong genetic component, as separated twins eventually developed a similar personality to their parents. ${ }^{6}$ Also, empirical studies have consistently shown that adoptive children show greater resemblance to their biological parents, rather than their adoptive, or environmental parents. ${ }^{7}$ However, research done by Plomin has shown that the predominant influence of personality has been traced back to environment. ${ }^{8}$ Even though twins share genetic material, their surroundings and experiences will shape them into who they are, aside from their DNA shared from their biological parents, if the Minnesota Twin Study was used as an example.

Ever since the publications of the Blood Type + Personality Correlation phenomenon, blood type has become a critical component in the lives of Japanese. Blood type influences job interviews, marriages and the reputation of individuals in society. Businesses in Japan also sell products catered to specific blood types and sports training is developed specifically for each blood type. Discrimination has even occurred in Japan- "bura hara"- based off an individual's blood type and their alleged personality traits. BBC News reports that "In July 2011, Minister for Reconstruction Ryu Matsumoto resigned after being criticized for making insensitive remarks. He blamed his blood type". ${ }^{9}$ Blood type is clearly a prime component in the lives of Japanese people, but does this belief stand scientifically?

Tokeji Furukawa has made his correlation between blood type and personality apparent through highlighting the purported distinct traits that an individual has due to their blood type. Walden University has written about Furukawa's theory as shown in Table $2 .^{10}$

Research to test these variables has been published by varying sources including Nawata $(2004)^{11} \mathrm{Wu}$, Lindsted, Lee $(2005)^{12}$ and Tscuchimine, Saruwatari, Kaneda, Yasui-Furukori (2015)..$^{13}$ These studies differ from our research as the latest paper has been published more than 5 years ago. In addition, 
some results received by the published journals were of mixed consensus. The research was also targeted among Japanese and Taiwanese individuals; cultures where the Blood-Type correlation ideal persists to this day. The present research in this paper includes any nationality, predominantly living in America, which limits the bias that may arise when the participants are surveyed. This signifies they are not mentally predisposed to the notion that blood type and personality are affiliated, which may impact them to answer the survey with the ideal, a belief that the Asian participants may have.

Table 2: This table describes the correlation that Ketsueki-Gata describes, categorizing blood types with different personality traits. The table shows that each type is thought to have different dispositions, which is how individuals are viewed in society.

\begin{tabular}{|l|l|l|l|}
\hline Type A: & Type B: & Type AB: & Type O: \\
\hline $\begin{array}{l}\text { Earnest, creative, } \\
\text { sensible, stubborn, } \\
\text { tense }\end{array}$ & $\begin{array}{l}\text { Passionate, active, } \\
\text { selfish, irresponsible }\end{array}$ & $\begin{array}{l}\text { cool, controlled, } \\
\text { rational, critical, } \\
\text { indecisive }\end{array}$ & $\begin{array}{l}\text { confident, strong, cold, } \\
\text { unpredictable }\end{array}$ \\
\hline
\end{tabular}

\section{- Methods}

\section{Human Participant Research:}

As this is a human participant study, there will always be risks even if minimal. For this study, psychological risks were considered as a potential issue. Participants were made aware that this was solely a research study and did not formally indicate any correlation or lack thereof. Risks were minimized by informing participants that they had the right to stop taking the survey at any time; they were also be notified that any individual who felt uncomfortable taking a personality assessment or providing their blood type should not participate in this study as they are part of the vulnerable population.

Participants were ages $18+$ and gender, race and ethnicity were not considered as identity remained anonymous.

Participants were a combination of individuals in communication with the researcher prior to the study, and individuals who were willing to participate in this survey even if the researcher did not have a connection with them, as the survey had been forwarded from family and friends to others living in their area/others willing to participate. This survey was a text message in which a consent message will be sent to them and a link to complete the survey.

Participants were asked to complete a survey in which they provide their blood type and take a personality test from the International Personality Item Pool, which is described further in the procedures section. This survey took around 1-2 minutes to complete. Participants were not informed of the goal of this study prior to their involvement to limit bias.

Benefits to participants included that they were contributing to a research study aiming to prove/disprove the credibility of the belief that personality is impacted by blood type. They also engaged in retrospective activity as they reflected upon their character traits while completing the survey.

The research was approved by the school psychologist: $\mathrm{H}$. O'Brien, MS, Eds, Psy.D. It was reviewed by the school's Institutional Review Board who concluded that the study posed minimal risk, did not require a written minor assent form, a written parental permission form (as no participant was under the age of 18) and did not require a written informed consent form for participants older than 18 years of age. No identifiable information was collected. Email collection occurred through the Google Forms software was disabled. The only information received was the date and time the survey was submitted and the participants' responses.

The data will be stored in a secured google forms sheet, for a minimum of 5 years after the study has culminated. The researcher will be the only person with access to results before, during, and after experimentation, as it is her personal Google account with a confidential password.

\section{Procedure:}

An online survey was created through Google Forms asking participant about their blood type. The survey questions were based off the International Personality Item Pool (based on the Big 5 Personality Traits: Ocean (Openness to Experience, Conscientiousness, Extraversion, Agreeableness, and Neuroticism)) which also provides the scaling chart to convert responses to numerical values. ${ }^{14}$ This pool was created by Lewis Goldberg, which measures the Big 5 Personality Traits and has become the best accepted personality model in modern psychology. ${ }^{5}$ The first question of the survey asked if participant is aware of their blood type, and if answer is no, they were taken to the end of the survey. Otherwise, the participant continued with survey and provided their blood type.

Four questions for each of the five personality types were curated based off OCEAN categories from the International Personality Item Pool. The survey was linked to a Google Sheets page to collect data efficiently and then sent to participants through a text message to 126 individuals on December $5^{\text {th }}, 2019$. After a span of 2 weeks, the survey page was closed, and data collection and mathematical analysis began. Using the data received from the Google Sheets page from the Google Forms survey, the results were scored using the IPIP (International Personality Item Pool) scaling sheet, and total scores were added for each category of OCEAN. The obtained score for each category was then divided by the highest possible score as determined by IPIP. The scores were then multiplied by 100 to find percentile values and averages were found per OCEAN group.

After conducting the survey, the responses received were analyzed. However, some participants did not know their blood type, and some surveys were not completed in full. After removing these from the database, 100 responses remained. Using the IPIP Scale Score chart, the responses were computed and scaled to numerical values. Each answer from the personality test (strongly disagree, disagree, neutral, agree, strongly agree) was presented with a value from 1-5 depending on the "keyed value" (either positive or negative) of the question. Separated per blood type, the numbers were summed per blood type, placed into their respective OCEAN categories and averaged to find a value. This was repeated for every response until averages for each blood type and its respective OCEAN Category were received.

\section{- Results}

The average values per OCEAN category per blood type were graphed on a bar graph, where slight differences were 
apparent per blood type. After, the CHI Square statistical analysis was performed using Microsoft Excel software, as seen in the Figure 1 . The probability values ( $p$-values) received were $0.96,0.99,0.99,0.98$ and 0.97 for OCEAN respectively. $\mathrm{P}$ values range from $0-1$ and a higher $\mathrm{p}$ value leads to a failure to reject the null hypothesis. The high $\mathrm{p}$ values attained from the analysis provide evidence that there is no relationship between blood type and personality and the null hypothesis is failed to be rejected.

According to Table 3, the observed and expected values of the IPIP scores were calculated using CHI Square P Value test. The $\mathrm{P}$ value received was 0.98 , a very high $\mathrm{P}$ value that does not signify a statistically significant value. Table 4, 5, 6, and 7 , all show similar values as the $P$ values were in the high 90th percentiles, leading to values that are not statistically significant.

The tables do show some variances from the expected values, and these variances can also be seen through the Figures 3-7. However, the $\mathrm{P}$ value test confirms that these values are not statistically significant despite the score fluctuations from the expected values.

\section{Excel $P$ Value Formula}

\section{- tdist(x,deg_freedom,tails)}

Figure 1: : Excel $\mathrm{P}$ value formula that was used to calculate blood type/ questionnaire $\mathrm{P}$ value. $\mathrm{P}$ value provides evidence of the need to reject/fail to reject the null hypothesis.

\section{Blood Type and Personality Probability Values: Comparing} Observed vs Expected for an OCEAN category:

Table 3: This table displays the extraversion questions compared with blood type. $\mathrm{P}$ value using observed and expected values resulted to 0.99 , a large value leading to the failure of rejecting the null hypothesis. There is no relationship between blood type and extroversion.

\begin{tabular}{|lrrr|}
\hline $\begin{array}{l}\text { Blood } \\
\text { Type }\end{array}$ & Observed & Expected & P Value \\
\hline A- & 2.68 & 3 & $\mathbf{0 . 9 8 8 3 7 5 2}$ \\
\hline $\mathrm{A}+$ & 4.125 & 3 & \\
\hline $\mathrm{B}+$ & 3.5 & 3 & \\
\hline $\mathrm{AB}+$ & 3.25 & 3 & \\
\hline $\mathrm{O}-$ & 3.3 & 3 & \\
\hline $\mathrm{O}+$ & 2.93 & 3 & \\
\hline
\end{tabular}

Table 4: This table displays the agreeableness questions compared with blood type. P value using observed and expected values resulted to 0.98 , a large value leading to the failure of rejecting the null hypothesis. There is no relationship between blood type and agreeableness.

\begin{tabular}{|lrrr|}
\hline $\begin{array}{l}\text { Blood } \\
\text { Type }\end{array}$ & Observed & Expected & P Value \\
\hline A- & 2.68 & 3 & $\mathbf{0 . 9 8 8 3 7 5 2}$ \\
\hline $\mathrm{A}+$ & 4.125 & 3 & \\
\hline $\mathrm{B}+$ & 3.5 & 3 & \\
\hline $\mathrm{AB}+$ & 3.25 & 3 & \\
\hline $\mathrm{O}-$ & 3.3 & 3 \\
\hline $\mathrm{O}+$ & 2.93 & 3 \\
\hline
\end{tabular}

Table 5: This table displays the conscientiousness questions compared with blood type. P value using observed and expected values resulted to 0.99 , a large value leading to the failure of rejecting the null hypothesis. There is no relationship between blood type and conscientiousness.

\begin{tabular}{|llll|}
\hline $\begin{array}{l}\text { Blood } \\
\text { Type }\end{array}$ & Observed & Expected & P Value \\
\hline A- & 3.5 & 3 & 0.9892896 \\
\hline$A+$ & 3.97 & 3 & \\
\hline$B+$ & 3.43 & 3 & \\
\hline$A B+$ & 3.25 & 3 & \\
\hline$O-$ & 3.3 & 3 & \\
\hline$O+$ & 3.43 & 3 & \\
\hline
\end{tabular}

Table 6: The table displays the neuroticism questions compared with blood type. $\mathrm{P}$ value using observed and expected values resulted to 0.97 , a large value leading to the failure of rejecting the null hypothesis. There is no relationship between blood type and neuroticism.

\begin{tabular}{|llll|}
\hline $\begin{array}{l}\text { Blood } \\
\text { Type }\end{array}$ & Observed & Expected & P Value \\
\hline A- & 3.5 & 3 & 0.9736089 \\
\hline$A+$ & 4.19 & 3 & \\
\hline$B+$ & 2.9 & 3 & \\
\hline$A B+$ & 3.83 & 3 & \\
\hline$O-$ & 3.41 & 3 & \\
\hline$O+$ & 3.15 & 3 & \\
\hline
\end{tabular}

Table 7: The table displays the openness to experience questions compared with blood type. P value using observed and expected values resulted to 0.96 , a large value leading to the failure of rejecting the null hypothesis. There is no relationship between blood type and openness to experience.

\begin{tabular}{|llll|}
\hline $\begin{array}{l}\text { Blood } \\
\text { Type }\end{array}$ & Observed & Expected & P Value \\
\hline A- & 3.75 & 3 & 0.9613414 \\
\hline A+ & 4.13 & 3 & \\
\hline$B+$ & 3.7 & 3 & \\
\hline$A B+$ & 3.5 & 3 & \\
\hline O- & 3.67 & 3 & \\
\hline O+ & 3.13 & 3 & \\
\hline
\end{tabular}

CONSCIENTIOUSNESS: BLOOD TYPE VS CONSCIENTIOUSNESS VALUES

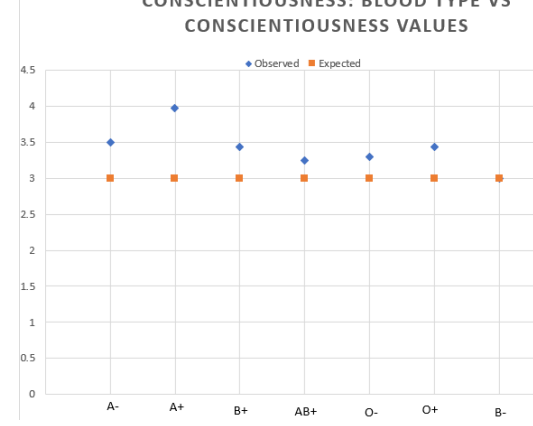

Figure 2: This graph illustrates the Conscientiousness IPIP Scores for each blood type. This graph shows deviations from the expected values, with scores being higher for all blood types in regard to conscientiousness. 


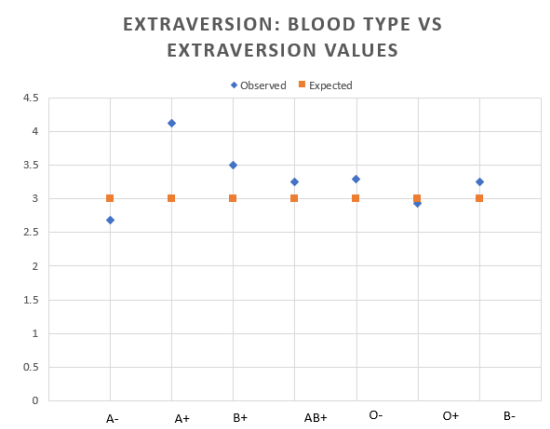

Figure 3: This graph illustrates the Extraversion IPIP Scores for each blood type. This graph shows deviations from the expected values, with scores being higher for all blood types except $\mathrm{A}$ - and $\mathrm{O}+$ in regard to extraversion.

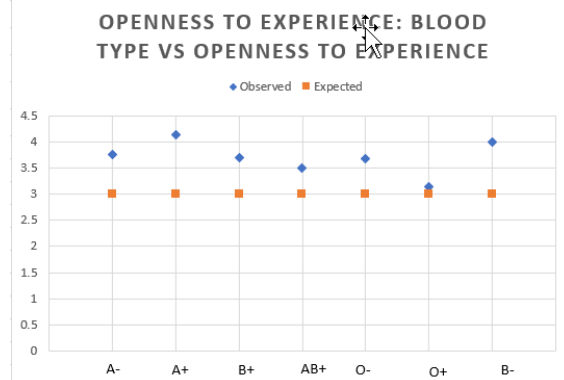

Figure 4: This graph illustrates the Openness to Experience IPIP Scores for each blood type. This graph shows deviations from the expected values, with scores being higher for all blood types in regard to openness to experience.

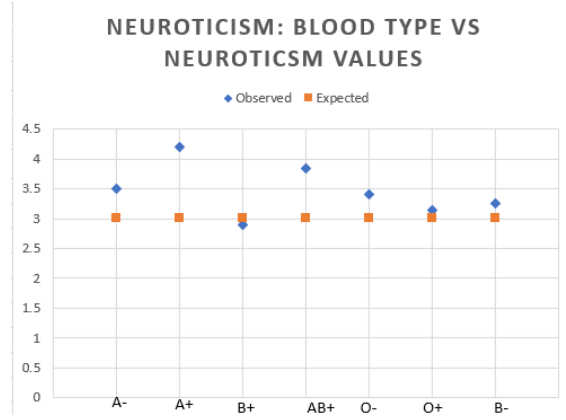

Figure 5: The graph identifies the neuroticism IPIP Scores for each blood type. This graph shows deviations from the expected values, with scores being higher for all blood types except $\mathrm{B}+$ in regard to neuroticism.

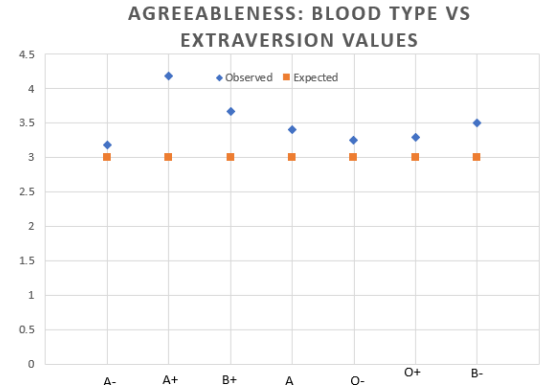

Figure 6: This graph illustrates the Agreeableness IPIP Scores for each blood type.This graph shows deviations from the expected values, with scores being higher for all blood types in regard to agreeableness

\section{Conclusion}

Through the statistical analysis of 100 adults, using their blood types and personality questionnaire responses, a correlation was not found between blood type and personality. The $\mathrm{P}$ values received from the Excel Software CHISQUARE test were in the high 90 th percentiles, and a result under $5 \%$ would be considered statistically significant, whereas this result is not significant. Although the scatterplot shows deviations from expected values for all blood type-personality characteristic combinations, the CHISQUARE test does not support any correlation. The high $\mathrm{P}$ value failed to reject the null hypothesis "The blood type of an individual has no impact of their personality traits as represented by openness, conscientiousness, extraversion, agreeableness, and neuroticism".

The overall hypothesis has been supported by the results. Personality may have a genetic component, as seen in the Minnesota Twin Study, but is not dependent on an individual's blood type. It may, however, be influenced by external forces, such as environment. ${ }^{15}$ Personality tends to be molded by experiences and events that a person has been through, rather than a strict biological component. Standards, such as profiling humans according to blood type, as seen in Japan, set individuals into a mold they cannot escape, which is unreasonable as shown by studies done in Japan and once again through this study, which focuses on all participants regardless of their background. ${ }^{11}$ Blood type should not denote the "expected" characteristics of an individual. Although genetic components may have an impact, personality is not dependent on blood type as can be seen from this study and the results received.

\section{Acknowledgements}

The author thanks her AP Chemistry teacher, Mrs. Bhagyashree Kulkarni and Mr. Alexandre Da Silva of Middleton High School and Mr. Dan McFarland of Hillsborough County Public Schools for assisting during the research process. She also thanks her parents for encouraging her to pursue research and assisting her through her study.

\section{References}

1. What Your Blood Type Says About You: A Fun, Educational Look at Your Health and Personality | Walden University. https://www.waldenu.edu/ programs/health/resource/what-your-blood-typesays-about-you.

2. In Japan, you are what your blood type is - Japan Today. https://japantoday.com/category/ features/lifestyle/in-japan-you-are-what-yourblood-type-is.

3. Karl Landsteiner (1868-1943) | The Embryo Project Encyclopedia. https://embryo.asu.edu/ pages/karl-landsteiner-1868-1943.

4. Big 5 Personality Traits. https://www.apa.org/monitor/2013/03/big-five.

5. Big Five Personality Test. https://openpsychometrics. org/tests/IPIP-BFFM/ (accessed Oct 23, 2020).

6. Nancy, S. Born Together-Reared Apart: The Landmark Minnesota Twin Study. 2012. 
7. Plomin, R.; Loehlin, J.; DeFries, J. Genetic And Environmental Components Of "Environmental" Influences. Developmental Psychology 1985, 21 (3), 391-402.

8. Stangor, C.; Walinga, J. 12.3 Is Personality More Nature or More Nurture? Behavioural and Molecular Genetics. https://opentextbc.ca/ introductiontopsychology/chapter/11-3-ispersonality-more-nature-or-more-nurturebehavioral-and-molecular-genetics/ (accessed Oct 23, 2020).

9. Japan's obsession with blood types. https://www.bbc.com/news/magazine-20170787.

10. Walden University. What Your Blood Type Says About You: A Fun, Educational Look at Your Health and Personality. https://www.waldenu.edu/ programs/health/resource/what-your-blood-typesays-about-you (accessed Oct 5, 2020).

11. Nawata, K. No Relationship Between Blood Type And Personality: Evidence From Large-Scale Surveys In Japan And The US. The Japanese journal of psychology 2014, 85 (2), 148-156.

12. Wu, K.; Lindsted, K.; Lee, J. Blood Type And The Five Factors Of Personality In Asia. Personality and Individual Differences 2005, 38 (4), 797-808.

13. Tsuchimine, S.; Saruwatari, J.; Kaneda, A.; YasuiFurukori, N. ABO Blood Type And Personality Traits In Healthy Japanese Subjects. PLOS ONE 2015, 10 (5), e0126983.

14. IPIP Home. https://ipip.ori.org/ (accessed Oct 23, 2020). 15. Nakao, K.; Takaishi, J.; Tatsuta, K.; Katayama, H.; Iwase, M.; Yorifuji, K.; Takeda, M. The influences of family environment on personality traits. https://onlinelibrary.wiley.com/doi/full/10.1046/ j.1440-1819.2000.00642.x (accessed Oct 5, 2020).

\section{- Author}

Muni Tanmayi Bondu is a senior at Middleton Magnet High School in Tampa, Florida in the Biomedical Science/ Biotechnology program. She is interested in studying computer science and its applications within the biomedical field in the future. Muni loves volunteering, traveling and photography. 